\title{
ANÁLISE DA RECUPERAÇÃO DA LANOLINA PROVENIENTE DO BENEFICIAMENTO DA LÃ DE OVINOS
}

\author{
J. M. do PRADO ${ }^{1}$, C. G. FLORES ${ }^{1}$, E. MENDONÇA ${ }^{1}$, T. R. de $\operatorname{SOUZA}^{1}$, A. R. F. \\ ALMEIDA $^{1}$, V. T. CREXI ${ }^{2}$ \\ ${ }^{1}$ Universidade Federal do Pampa, Departamento de Engenharia Química \\ ${ }^{2}$ Universidade Federal do Pampa, Departamento de Engenharia de Alimentos \\ E-mail para contato: j_martins_bta@hotmail.com
}

\begin{abstract}
RESUMO - A ovinocultura é uma das principais atividades de pecuária desenvolvida no Rio Grande do Sul, principalmente na Campanha, com inverno rigoroso e propício para criação de ovinos lanados. O processo de beneficiamento da lã gera um subproduto denominado lanolina bruta, porém, parte deste subproduto é perdido, sendo arrastado com a água de lavagem para o tratamento de efluentes. Uma forma de minimizar essa perda é aplicar tecnologias adequadas para a recuperação da lanolina bruta, uma destas é a centrifugação. Neste contexto, foram estudas condições de centrifugação em uma centrifuga de copos, com utilização de um solvente, o etanol, visando obter maior recuperação desse subproduto. A primeira etapa consistiu na caracterização físico-química (massa específica, umidade, índice de acidez e saponificação) da lanolina purificada e da lanolina cedida por uma empresa local de beneficiamento de lã. Na segunda etapa, realizou-se o estudo da quantidade de solvente a ser utilizado, trabalhando-se com concentrações de 10 e $50 \%$ de etanol. Na terceira etapa, desenvolveu-se o estudo da centrifugação, operando com velocidade de rotação de 1000 e $4000 \mathrm{rpm}$, e tempo de retenção de 20 minutos. Os dados obtidos foram analisados em um planejamento experimental fatorial $2^{2}$ com duplicata, tendo como resposta a melhor condição para recuperação da lanolina bruta, sendo esta obtida na velocidade de rotação de $4000 \mathrm{rpm}$, e concentração de $50 \%$, que resultou na recuperação de $1,300 \pm 0,001 \%$ de lanolina bruta.
\end{abstract}

\section{INTRODUÇÃO}

A ovinocultura é uma das atividades mais desenvolvidas no estado do Rio Grande do Sul, principalmente na região da Campanha. Segundo o IBGE (2010), o estado se destaca como o maior produtor de ovinos do Brasil, com 22,90\% do efetivo nacional, sendo seguido pelo estado da Bahia com 18,00\% do efetivo.

Devido a Região Sul ter um inverno muito rigoroso, esta torna-se ideal para a criação de ovinos lanados. Os ovinos que mais produzem lã são os das raças: Merino Australiano, Ideal, Corriedale entre outras. O estado do Rio Grande do Sul detém 98,50\% da produção de lã nacional (IBGE, 2010). 
A principal aplicação da lã de ovinos é nas indústrias de beneficiamento, onde a mesma, proveniente dos produtores ou de cooperativas de ovinos, é transformada em tops de lã. No beneficiamento da lã também se obtém alguns subprodutos, dentre os quais se destaca a lanolina bruta, considerada o principal deles. O processo de recuperação da lanolina se justifica pelo retorno financeiro (venda da lanolina) e ambiental (redução da carga orgânica no efluente) (Rodrigues, 2010).

A lanolina bruta (do latim lana, lã) é uma cera natural encontrada na lã de ovinos. É uma substância complexa, formada por uma mistura de ésteres e poliésteres de alcoóis de cadeia longa e por ácidos graxos livres, estes provenientes da secreção das glândulas sebáceas dos ovinos encontradas na lã (Martins et al., 2005).

O processo de extração da lanolina bruta ocorre nas indústrias de beneficiamento de lã, na sua etapa de lavagem com água quente entre 30 e $40^{\circ} \mathrm{C}$ (ponto de fusão da lanolina), sabão e detergente. Porém sua recuperação ocorre a partir da centrifugação dessa solução de lavagem. $\mathrm{Na}$ centrifugação, a temperatura deve ser controlada entre 80 e $90^{\circ} \mathrm{C}$ para diminuir a viscosidade da solução, facilitando sua recuperação (Carreira, 2006).

O processo de recuperação da lanolina bruta pode ser dado através de métodos físicos como a decantação ou a centrifugação, dita anteriormente, e ainda por métodos químicos, através da utilização de um solvente para a extração líquido-líquido ou sólido-líquido, onde o componente a ser extraído é solúvel no solvente e os outros componentes são insolúveis (Foust et al., 1982).

A lanolina possui uma larga aplicação industrial, principalmente nos setores farmacêuticos e cosméticos. É uma substância eficaz que age como uma barreira de umidade e lubrificante (Quinzo, 2011). É muito utilizada como hidratante para pele, sobreengordurante em cabelos, cicatrizantes, impermeabilizantes, lubrificantes, protetores e amaciante para couro entre outros (Almeida, 2006).

Em vista disso, e visando contribuir para melhores condições de recuperação da lanolina bruta, este trabalho tem como objetivo principal obter melhores resultados utilizando a centrifugação, com adição de um solvente, o etanol.

\section{MATERIAIS E MÉTODOS}

Matéria Prima: Para a realização deste trabalho, foi utilizada água de lavagem proveniente da segunda barca do processo de lavagem da lã, conforme demonstra a Figura 1, de uma indústria de beneficiamento de lã localizada na cidade de Bagé/RS. A água de lavagem foi adquirida em apenas um lote, garantindo as mesmas características físicoquímicas da matéria prima para todos os experimentos. 


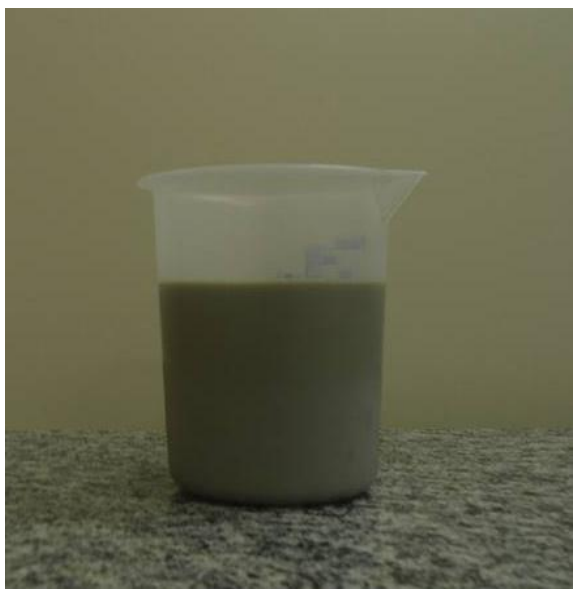

Figura 1 - Amostra da água de lavagem.

Recuperação da Lanolina: A preparação das amostras foi realizada da seguinte forma: foram separadas duas amostras da água de lavagem, onde se adicionou $10 \%$ de etanol com concentração $92,80^{\circ}$ a primeira, e $50 \%$ de etanol com concentração $92,80^{\circ}$ a segunda. As misturas entre as amostras da água de lavagem e o etanol foram feitas cada qual em um funil de separação, agitado o para que houvesse interação entre as amostras e o solvente.

Para a centrifugação das misturas, utilizou-se uma centrifuga de copos, onde foram colocados quatro copos com aproximadamente $45 \mathrm{~mL}$ da mistura com $10 \%$ de etanol, logo após, realizado o mesmo com a mistura de $50 \%$ de etanol, conforme observado na Figura 2.

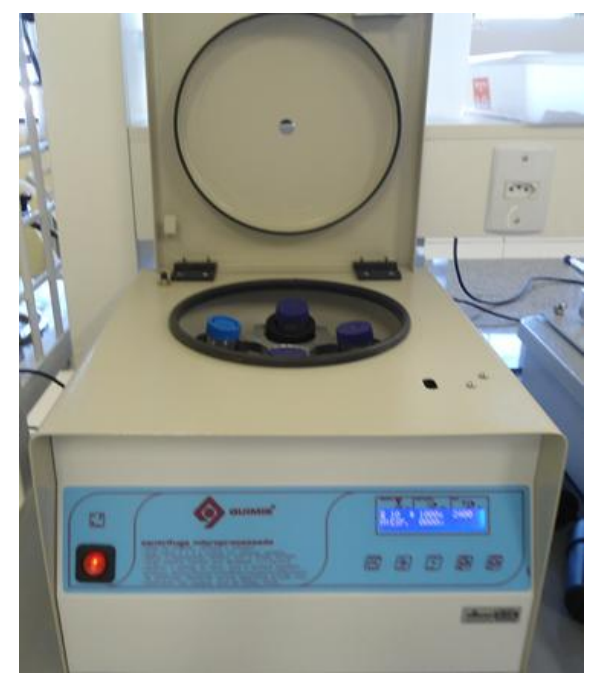

Figura 2 - Centrífuga de copos.

Para a realização dos ensaios de centrifugação utilizaram-se parâmetros prédeterminados. A organização dos experimentos seguiu um planejamento experimental fatorial $2^{2}$ com duplicata. As variáveis estudadas no processo foram à velocidade de centrifugação e a 
quantidade de solvente utilizado, sendo o tempo de centrifugação fixado em 20 minutos. Na Tabela 1 são apresentadas as condições experimentais de centrifugação estudadas neste trabalho, onde os ensaios estão dispostos de acordo com o planejamento experimental fatorial $2^{2}$ com duplicata.

Tabela 1 - Condições experimentais de centrifugação.

\begin{tabular}{cccc}
\hline Ensaio & $\begin{array}{c}v \\
(\mathrm{rpm})\end{array}$ & $\begin{array}{c}\text { Concentração de } \\
\text { solvente }(\%)\end{array}$ & $\begin{array}{c}\mathrm{t} \\
(\mathrm{min})\end{array}$ \\
\hline 1 & 1000 & 10 & 20 \\
2 & 4000 & 10 & 20 \\
3 & 1000 & 50 & 20 \\
4 & 4000 & 50 & 20 \\
\hline
\end{tabular}

Após a centrifugação obteve-se a separação do sólido e da parte líquida. A parte líquida foi acondicionada em frascos de $250 \mathrm{~mL}$. Para a recuperação do solvente foi utilizado um evaporador rotativo acoplado a uma bomba de vácuo, como mostra a Figura 3.

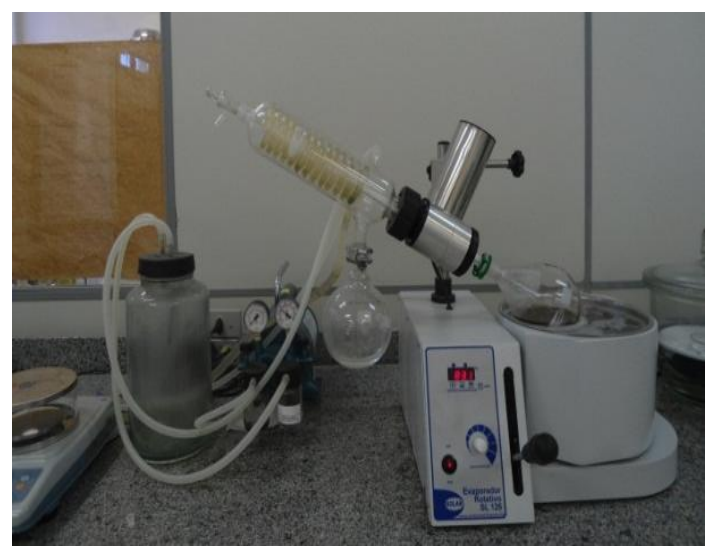

Figura 3 - Rotaevaporador.

Os parâmetros físicos do rotaevaporador foram mantidos constantes: a temperatura do banho a $70{ }^{\circ} \mathrm{C}$ e a pressão dentro do equipamento a $500 \mathrm{mmHg}$.

Através das respostas do planejamento experimental fatorial, pela quantidade da lanolina bruta recuperada, foi possível determinar a melhor e a pior condição de centrifugação. A quantidade de lanolina bruta obtida através do método utilizado foi determinada através da Equação 1.

$$
\text { Quantidade Extraída }=\frac{m_{\text {gordura }}}{m_{\text {amostra }}} .100
$$


As análises físico-químicas da melhor condição foram comparadas com as análises físico-químicas de uma amostra de lanolina cedida pela empresa e uma amostra de lanolina purificada (comercial), sendo determinada a massa específica, umidade, índice de acidez, índice de iodo e índice de saponificação.

\section{RESULTADOS E DISCUSSÕES}

A Tabela 2 apresenta as variáveis independentes, velocidade de rotação e concentração do solvente, utilizadas na forma codificada, e também está disposta a quantidade da lanolina bruta recuperada através da rotaevaporação.

Tabela 2 - Matriz do Planejamento Experimental Fatorial $2^{2}$ com Duplicata.

\begin{tabular}{c|c|c|c|c|c}
\hline Ensaio & $\mathrm{X}_{1}$ & $\mathrm{X}_{2}$ & $\begin{array}{c}v \\
(\mathrm{rpm})\end{array}$ & $\begin{array}{c}{[]} \\
\text { solvente }\end{array}$ & $\begin{array}{c}\text { Quantidade da lanolina } \\
\text { bruta recuperada (\%) }\end{array}$ \\
\hline 1 & -1 & -1 & 1000 & 10 & 0 \\
2 & +1 & -1 & 4000 & 10 & 0 \\
3 & -1 & +1 & 1000 & 50 & $1,1000 \pm 0,0001$ \\
4 & +1 & +1 & 4000 & 50 & $1,300 \pm 0,001$ \\
\hline
\end{tabular}

Para uma melhor compreensão da influência das variáveis, velocidade de rotação e concentração do solvente, é apresentada a seguir a análise do Diagrama de Pareto, Figura 4, referente ao planejamento experimental realizado. Nessa figura, a magnitude dos efeitos sobre a resposta quantidade da lanolina bruta recuperada é apresentado pelas colunas, enquanto a linha transversal representa a magnitude dos efeitos com significado estatístico para $p=0,05$, ou seja, os fatores que são estatisticamente significativos ao nível de $95 \%$ de confiança.

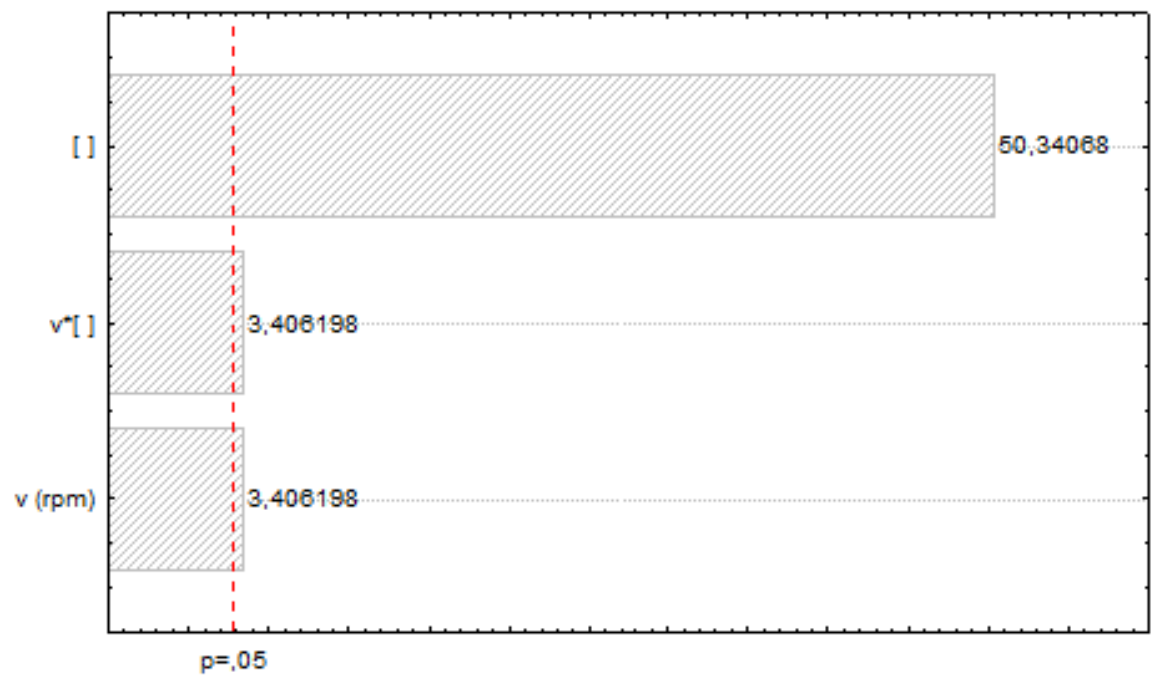

Figura 4 - Diagrama de Pareto. 
Analisando a Figura 4, observa-se que o fator concentração foi o que influenciou de forma mais significativa à resposta quantidade da lanolina bruta recuperada, atingindo um efeito padronizado de aproximadamente 50,34. Outros fatores que também exerceram uma influência na resposta quantidade da lanolina bruta recuperada foram o efeito principal velocidade de rotação e a sua interação com o efeito concentração, com valores padronizados de aproximadamente 3,40. Todos os efeitos foram positivos, ou seja, a quantidade de gordura recuperada foi maior ao passar do nível inferior para o nível superior. utilizado.

A Figura 5 apresenta o quadrado de respostas do planejamento experimental fatorial $2^{2}$

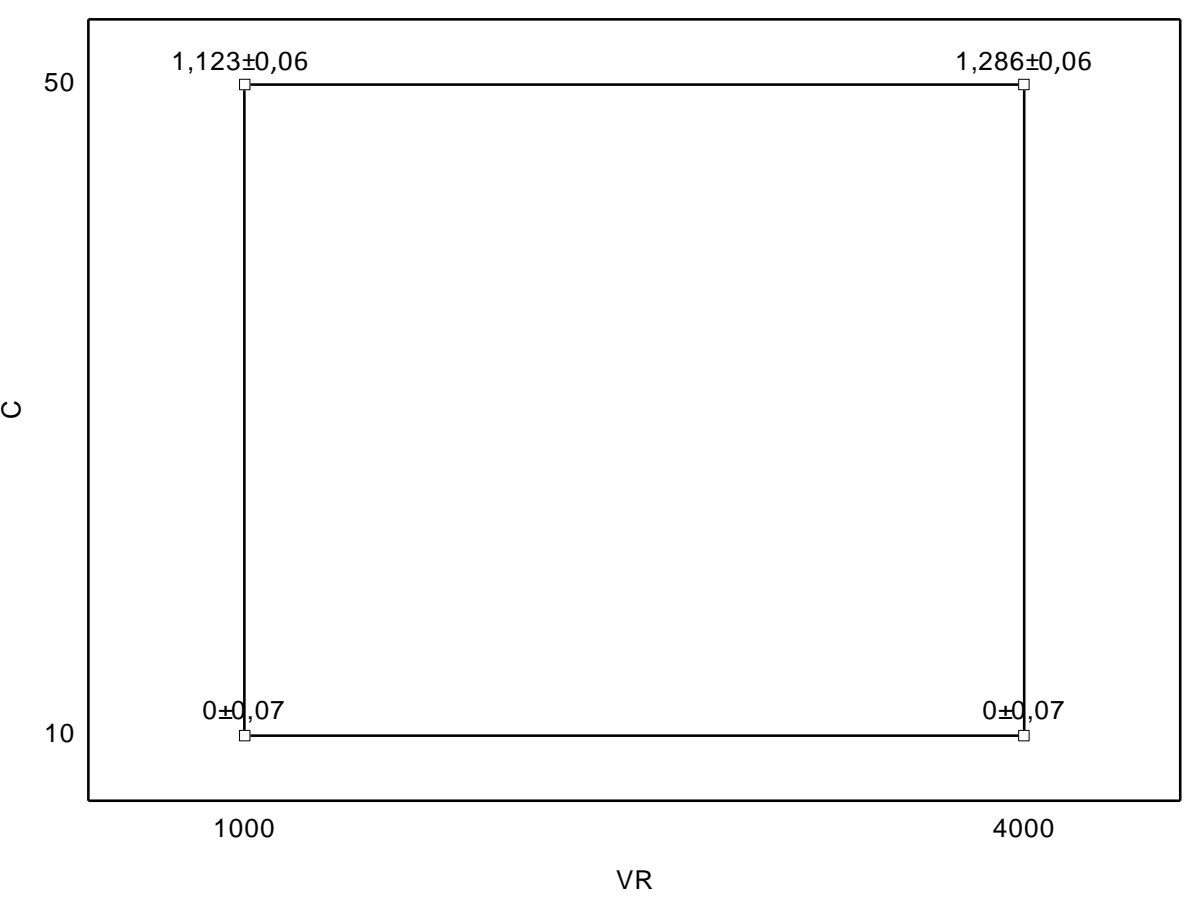

Figura 5 - Quadro de respostas.

Analisando a Figura 5 nota-se que quando a concentração se encontra no nível mais baixo, a resposta é zero independente da velocidade de rotação, ou seja, com $10 \%$ de concentração do solvente não houve separação na mistura. Quando a concentração atinge seu nível superior se obtém resposta, independente da velocidade de rotação. Com a concentração e a velocidade de rotação mantidas no nível superior se obtém a melhor resposta, ou seja, com uma quantidade recuperada de $1,28 \%$.

A explicação física se dá devido à quantidade de $10 \%$ de etanol ser insuficiente para que ocorra interação entre as moléculas do solvente e da água de lavagem, diferente do que acontece com uma mistura de 50\%. Quanto maior a velocidade de rotação maior a separação entre o sólido e o líquido, porque a separação ocorre pela diferença de massa específica. 
A lanolina bruta recuperada na melhor condição do planejamento experimental fatorial $2^{2}$, a amostra de lanolina cedida pela empresa e a lanolina purificada e desodorizada, foram submetidas às análises físico-químicas e os resultados se encontram dispostos na Tabela 3.

Tabela 3 - Resultados das Análises Físico-Químicas.

\begin{tabular}{lcccc}
\hline Lanolina & $\begin{array}{c}\text { Massa Específica } \\
\left(\mathrm{kg} / \mathrm{m}^{3}\right)\end{array}$ & $\begin{array}{c}\text { Umidade } \\
(\%)\end{array}$ & $\begin{array}{c}\text { Índice de Acidez em } \\
\text { Ácido Oleico } \\
(\mathrm{g} / 100 \mathrm{~g})\end{array}$ & $\begin{array}{c}\text { Índice de } \\
\text { Saponificação } \\
(\mathrm{g} / \mathrm{mg})\end{array}$ \\
\hline Bruta & $930,100 \pm 0,001$ & $2,2 \pm 0,2$ & $0,10 \pm 0,08$ & $45 \pm 6$ \\
Empresa & $918 \pm 9$ & $2,2 \pm 0,2$ & $0,6 \pm 0,1$ & $90 \pm 3$ \\
Purificada & $927,100 \pm 0,001$ & $2,2 \pm 0,2$ & $0,700 \pm 0,001$ & $78 \pm 3$ \\
\hline
\end{tabular}

$\mathrm{Na}$ Tabela 3 é possível verificar que os índices de acidez e saponificação não se encontram com valores próximos para os três tipos de lanolina analisadas. Os resultados também não podem ser comparados com a legislação da ANVISA, que para a lanolina é inexistente.

Os valores encontrados para a massa específica e a umidade dos três tipos de lanolina estudada estão coerentes e se encontram de acordo com Caetano (2012).

O índice de saponificação da lanolina cedida pela empresa se encontra de acordo com Adeps Lanae (2009) e Batistella (1999), já para a lanolina bruta, o mesmo se encontra com um valor abaixo do esperado, isso se dá devido ao solvente não ter sido evaporado totalmente. O mesmo acontece com a lanolina purificada, que também apresenta um valor abaixo de valores encontrados na literatura, porém, diferentemente da lanolina bruta, esta passou por um processo de purificação, onde é refinada, desodorizada, descorada e secada. Durante a desodorização, compostos voláteis, com menos peso molecular, podem ser arrastados. Se combinarmos a massa específica com o índice de saponificação para as amostras de lanolina bruta e purificada, estes se encontram de acordo porque quanto mais diluída a amostra maior a sua massa específica e menor o índice de saponificação.

O índice de acidez em ácido oleico para a lanolina bruta está de acordo com Adeps Lanae (2009) e Batistella (1999), onde segundo estes autores, o índice de acidez deve ser inferior a $0,600 \mathrm{~g} / 100 \mathrm{~g}$. Os resultados para a acidez da lanolina da empresa e para a purificada podem ter sofrido interferência pela temperatura elevada utilizada no processo, nos quais são submetidas. A elevação da temperatura faz com que ocorra a hidrólise da molécula, formando mais ácidos graxos livres.

As diferentes raças de ovelhas utilizadas em uma indústria de beneficiamento de lã e a alimentação de cada uma delas podem ter influenciado na composição das amostras de lanolina, explicando assim o porquê de alguns parâmetros físico-químicos apresentarem-se diferentes. 


\section{CONCLUSÃO}

Este trabalho possibilitou analisar a separação da lanolina bruta da água de lavagem de uma maneira diferente, com a utilização de um solvente, gerando outra alternativa para as industrias beneficiadoras de lã.

Os fatores concentração do solvente e velocidade de rotação influenciaram na resposta quantidade da lanolina bruta recuperada, tendo um efeito positivo sobre ela. Com o aumento da concentração e da velocidade de rotação, a quantidade de lanolina bruta recuperada foi de $1,300 \pm 0,001 \%$. Dessa forma, a melhor condição encontrada para a centrifugação com uma maior recuperação da lanolina bruta se deu na concentração de $50 \%$ de solvente e na velocidade de rotação de $4000 \mathrm{rpm}$.

\section{REFERÊNCIAS}

ADEPS LANAE. Lanolina. Disponível em: http://www.adeps.com.ar/lanolinas.html, 2009. Acesso em 12/02/2014.

ALMEIDA, C. M. P. R. Modelo Gestão Estratégica de Cadeias de Organização: um estudo exploratório. (Tese de Doutorado) Programa de Pós-Graduação em Administração, USP SP, 2006.

BATISTELlA, C. B. Tecnologia de Destilação Molecular: da modelagem matemática à obtenção de dados experimentais aplicada a produtos de química fina. (Tese de Doutorado). Pós Graduação de Processos Químicos, UNICAMP - SP, 1999.

CAETANO, M. Plastificantes de Origem Animal. <http://www.ctb.com.pt $/$ ?page_id= 5470> 2012. Acessado em 12/02/2014.

CARREIRA, M. F. Sistema de Tratamento de Efluente Têxteis. (Tese de Doutorado). Programa de Pós Graduação em Engenharia de Produção, UFSC - SC, 2006.

FOUST, A. S.; WENZEL, L. A.; CLUMP, C.W., MAUS, L.; ANDERSEN, L.B. Princípios das operações unitárias. $2^{\circ}$ Ed.,Rio de Janeiro, 1982.

IBGE - Institudo Brasileiro de Geografia e Estatística. Produção da Pecuária Municipal. Rio de Janeiro: IBGE, 2010. Disponível em: < http://www.ibge.gov.br/home/estatistica/economia/ ppm/2010/ppm2010.pdf. Acessado em 13/01/2014.

MARTINS, E. F.; PREIRA, L. M.; LIMA T. M.; AGUIAR, G. R.; CHEN, S. C.; FOLADOR, A.; PITHON-CURI, C. T.; CURI, R. Influência da Lanolina na Cicatrização. Saúde em Revista, 2005.

QUINZO, W, A. L. Obtención de Cueros Ovinos Afelpados con Frisa Corta Utilizando Diferentes Niveles de Aceite de Lanolina. (Tese de Doutorado). Facultad de Ciencias Pecuarias Escuela de Ingeniería Zootécnica, Equador, 2011.

RODRIGUES, B. S. Resíduos da agroindústria como fonte de fibras para elaboração de pães integrais. (Dissertação de Mestrado). Ciências e Tecnologia de Alimentos, USP - SP, 2010. 